\section{Use of structured letters to improve communication between hospital doctors and general practitioners}

\author{
J Rawal, P Barnett, B W Lloyd
}

Department of Paediatrics, North Middlesex Hospital NHS Trust, London

N18 1QX

J Rawal, senior registrar

B W Lloyd, consultant

\section{London N17 0DH}

P Barnett, general practitioner

Correspondence to:

Dr Rawal.

BMF 1993;307:1044

We recently showed that most general practitioners prefer letters from hospital doctors to contain a problem list. ${ }^{1}$ We have since investigated the attitude of general practitioners to a more structured letter containing both a problem list and a list of management proposals.

\section{Methods and results}

We first wrote to 100 randomly chosen general practitioners working in the catchment area of North Middlesex Hospital NHS Trust. We sent them each two different letters about the same fictional consultation with a paediatrician (box) and asked them to say which letter they preferred. Letter A, the structured letter, contained both a problem list and a list of management proposals. Letter B had the same problem list but the management proposals were included conventionally in the text. Most of the remaining text was identical.

We then reviewed 100 consecutive letters received in a general practice (PB's) about patients who had been newly referred to a hospital clinic. We determined the name of the hospital, the specialty and grade of the doctor who had written the letter, and whether the letter contained either a problem list or a list of management proposals.

Ninety two of the 100 general practitioners replied. Of these 92,81 preferred the structured letter, six preferred the letter with only a problem list, and five expressed no preference. The 100 letters analysed in the second part of the study had been written by doctors working at 16 different hospitals in 20 different specialties. Five letters were structured (with both a problem list and a list of management proposals)

\section{Letter A}

Dear Dr Smith,

Re: John Jones. Date of birth: 1/1/1981

789 Any Street, London N17 33X

\section{Problems}

Poorly controlled asthma

Passive smoker

Father in wheelchair after road traffic accident

\section{Management}

Prevention-Beclomethasone dipropionate dry powder $200 \mu \mathrm{g}$ twice a day (excellent inhaler technique).

Relief-Salbutamol dry powder 200-400 $\mu \mathrm{g}$ four hourly as needed.

Avoid cigarette smoke.

To casualty with bad attacks of asthma (danger peak flow level: $240 \mathrm{l} / \mathrm{min}$ ).

Thank you for referring this boy with frequent attacks of cough and wheeze. He misses a lot of school, sleeps badly, and is short of breath on exertion. Examination is normal. Peak flow today was $380 \mathrm{l} / \mathrm{min}$.

I was generally optimistic but emphasised the potential for serious attacks and the need for close family involvement in the management. The parents have a good grasp of how the peak flow meter can help in the recognition of severe episodes of asthma. He will be reviewed in one month. while five contained only a problem list and one only a list of management proposals. Eighty nine letters were conventionally compiled.

\section{Comment}

We found that nearly all the general practitioners in our study preferred the structured letter but few hospital doctors wrote such letters. We believe that our results are generally applicable. Because $92 \%$ of general practitioners in our randomly chosen sample responded their views are likely to be representative of British general practitioners as a whole. As in our previous study, our fictional letters came from a paediatrician, but we believe that we would have obtained similar results with other specialties.

There have been few studies of ways to improve communiction between hospital doctors and general practitioners. ${ }^{1-4}$ We have found no previous studies of the use of structured letters. Structured letters have four advantages over conventional letters. Firstly, they oblige the writer to state concisely what he or she thinks the patient's problems are and how they should be managed. Secondly, the reader can see at a glance what the writer's views are. Thirdly, they are shorter. Fourthly, general practitioners can transfer information more easily from structured letters to computerised patient records.

Writing structured letters requires discipline, but we think the effort is justified. When reading hospital notes most doctors turn to copies of past correspondence for a quick summary of the case. We believe that the first three of the four advantages listed above mean that structured letters summarise cases better than do conventional letters.

1 Lloyd BW, Barnett P. Use of problem lists in letters between hospital doctors and general practitioners. $B M F$ 1993;306:247.

2 De Alarcon R, de Glanville H, Hodson JM. Value of the specialist's report. BMF 1960;ii:1663-4.

3 Bado W, Williams CJ. Usefulness of letters from hospitals to general practitioners. $B M \mp 1984 ; 288: 1813-4$.

4 Newton J, Eccles M, Hutchinson A. Communication between general practitioners and consultants: what should their letters contain? $B M \mathcal{Y}$ 1992;304:821-4

(Accepted 9 fuly 1993)

\section{Letter B}

Dear Dr Smith,

Re: John Jones. Date of birth: 1/1/1981

789 Any Street, London N17 33X

Problems

Poorly controlled asthma

Passive smoker

Father in wheelchair after road traffic accident

Thank you for referring this boy with frequent attacks of cough and wheeze. He misses a lot of school, sleeps badly, and is short of breath on exertion. Examination is normal. Peak flow today was $380 \mathrm{l} / \mathrm{min}$.

I prescribed beclomethasone dipropionate dry powder $200 \mu \mathrm{g}$ twice a day as prevention and salbutamol dry powder $200-400 \mu \mathrm{g}$ four hourly as needed for relief of symptoms. His inhaler technique is excellent.

I was generally optimistic but emphasised the potential for serious attacks and the need for close family involvement in the management. The parents have a good grasp of how the peak flow meter can help in the recognition of severe episodes of asthma. I have given them a danger peak flow level of 240 (below this they should come to casualty). He will be reviewed in one month. 